\title{
The Application of Stem Cell Based Tissue Engineering in Spinal Cord Injury Repair
}

\section{Wanting Niu ${ }^{1,2}$ and Xiang Zeng ${ }^{3 *}$}

${ }^{1}$ Tissue Engineering Labs, Veterans Affair Boston Healthcare System, Boston, Massachusetts, USA

${ }^{2}$ Department of Orthopedics, Brigham and Women's hospital, Harvard Medical School, Boston, Massachusetts, USA

${ }^{3}$ Department of Neurosurgery, Brigham and Women's Hospital, Harvard Medical School, Boston, Massachusetts, USA

\begin{abstract}
Spinal Cord Injury $(\mathrm{SCl})$ results in the permanent functional impairment, leading to monoplegia, paraplegia or tetraplegia with tremendous social and economic burden. The intrinsic repair mechanism has been proven to be insufficient. The complex pathophysiology after injury imposes enormous challenging to functional recovery, given the most advanced medical intervention nowadays. Therefore, the development of effective therapeutic strategy for spinal cord injury management is in great need. Here we review a stem cell based tissue engineering approach under preclinical or clinical development for spinal cord injury, with a focus on promoting functional recovery after $\mathrm{SCl}$, aiming to provide some beneficial suggestion on stem cell based tissue engineering design.
\end{abstract}

Keywords: Tissue engineering; Stem cells; Biomaterial; Spinal cord injury; Regenerative medicine

\section{Introduction}

Sever Spinal Cord Injury (SCI) results in paraplegia or quadriplegia and there is no effective therapeutic regimen so far. In the U.S., it is estimated that the annual incidence of SCIs approximately 40 cases per million population or approximately 12,500 new cases each year, with a total of approximately 276,000 SCI patients [1]. Traffic accidents were typically the most common cause of SCI, followed by falls in the elderly population [2]. Traumatic SCI secondary to falls among the elderly may become an increasing public health problem as a result of rising aging population in developed countries [2-4]. This devastating disease brings the patients into disability, directly affects their life quality and imposes enormous psychological and economic burden to them and their families. Therefore, seeking effective strategies to treat spinal cord injuries has become one of the most challenging subjects in neuroscience research field.

The pathological and pathophysiological changes after SCI include primary injury and the following secondary injury $[5,6]$. Primary injury, caused by the initial mechanical force, directly damage the spinal cord tissue, causing neural cell death, nerve fiber breakage, hemorrhagic necrosis and edema. These processes happen immediately after injury and are irreversible. Secondary injuries include spinal cord ischemia and hypoxia, inflammation and immune response, excitotoxicity, glial scar and cavity formation. The secondary injury cascade can be managed by active medical intervention and hence has been the focus of SCI research [5,7]. Primary and secondary injuries lead to continuous expansion of the lesion zone. The necrotic neural tissue and demyelinated nerve fibers in the injury epicenter release various cytokines and chemokines to the surrounding tissue. As a result, the inflammation spreads to the adjacent spinal cord segments and causes hyperplasia and hypertrophy of astrocytes which will eventually form glial scar as a response to prevent further inflammatory diffusion. Meanwhile, the necrotic tissue is gradually cleaned by the scavenger cells, leaving the cavities inside the epicenter. The reactive astrocytes and some components of their extracellular matrix, (e.g., chondroitin sulfate proteoglycans), their secretions, as well as the cavities, set both physical and chemical barriers to the process of neuro regeneration [8]. This hostile microenvironment makes spinal cord regeneration difficult (Figure 1A). However, with the development of novel stem cell and tissue engineering based treatment strategies, there are some promising preclinical results which raise hope for SCI treatment in the future. Endeavor should be made not only towards an appropriate structural repair but also importantly a satisfactory functional recovery [9].

Neural tissue engineering repair strategy helps to repair the injured spinal cord, especially with large tissue loss or cavity formation through combinatorial approaches which involve biomaterial scaffold, cells and/ or bioactive molecules. The integration of implants into the host tissue has been shown to alleviate spinal cord injury, replace damaged tissue, promote regeneration and improve the paralyzed limb function (Figure 1B). To better utilize the repairing function of encapsulated stem cells and facilitate the integration of the scaffold to local host tissue, it is critical to choose a suitable biomaterial with the optimized physical, chemical and biological features. Although the criteria of biomaterial selection vary in different repairing strategies, we conclude that it should cover some basic character described as following:

(1) Good biocompatibility. After implanting into the host, the biomaterials per se and their degradation products have neither toxic side effects, nor potential cause of inflammatory response or immune rejection.

(2) Mechanical strength. Biomaterials should exert certain degree of mechanical strength in order to fill in the cavities and to function as scaffolds for implanted cells and host cells to attach and migrate and for axons to extend.

(3) Plasticity. Biomaterials should have the plasticity to be tailor into various shapes, according to the clinical needs.

(4) Biodegradable. Due to the functional delicacy and anatomical

${ }^{*}$ Corresponding author: Xiang Zeng, Department of Neurosurgery, Brigham and Women's Hospital, Harvard Medical School, Boston, MA 02132, USA, Tel: 01001249410; E-mail: xzeng4@partners.org

Received October 14, 2015; Accepted November 16, 2015; Published November 24, 2015

Citation: Niu W, Zeng X (2015) The Application of Stem Cell Based Tissue Engineering in Spinal Cord Injury Repair. J Tissue Sci Eng 6: 158. doi:10.4172/21577552.1000158

Copyright: ( $2015 \mathrm{Niu}$ W, et al. This is an open-access article distributed under the terms of the Creative Commons Attribution License, which permits unrestricted use, distribution, and reproduction in any medium, provided the original author and source are credited. 
Citation: Niu W, Zeng X (2015) The Application of Stem Cell Based Tissue Engineering in Spinal Cord Injury Repair. J Tissue Sci Eng 6: 158. doi:10.4172/2157-7552.1000158

Page 2 of 7
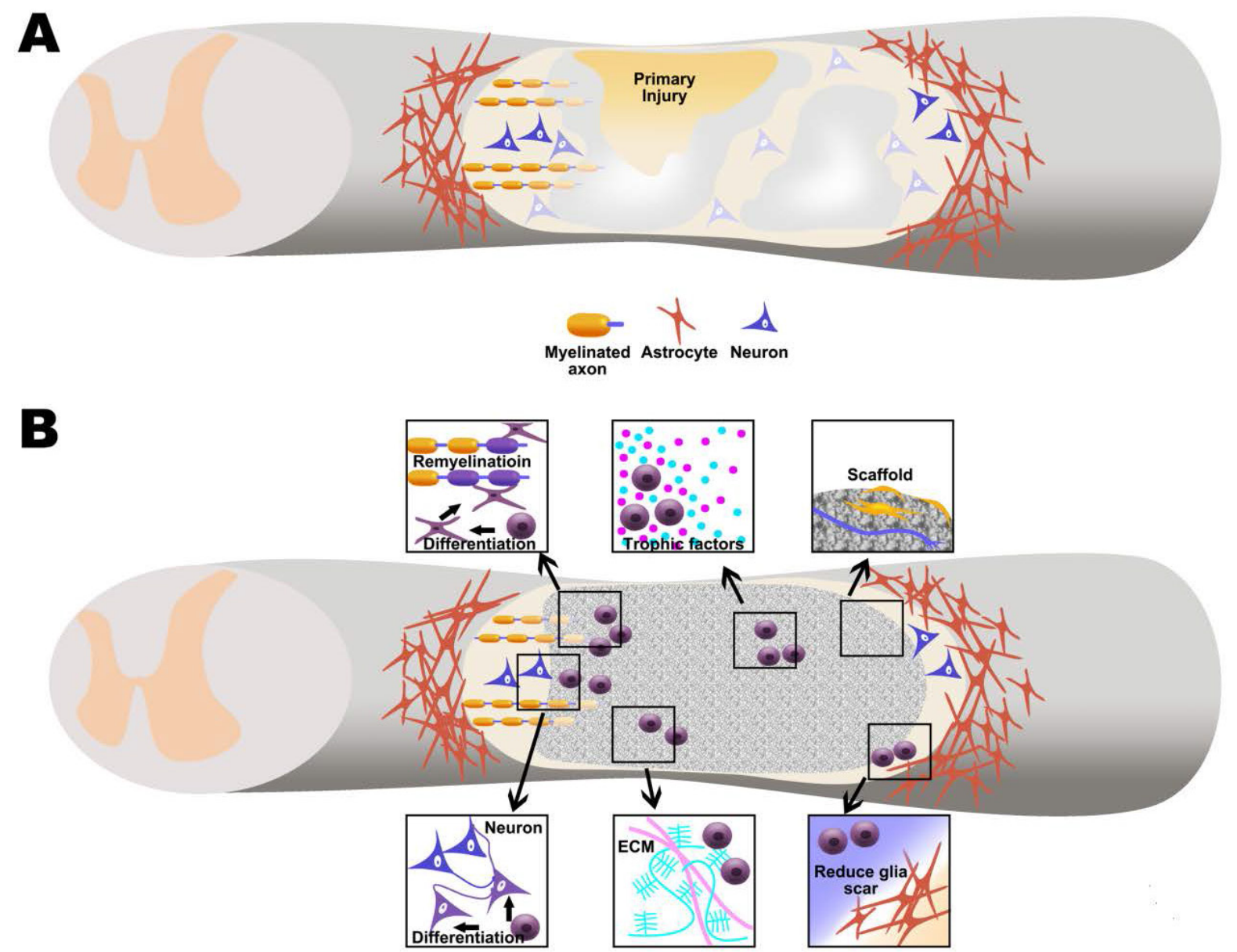

Figure 1: The pathophysiology of spinal cord injury and the potential mechanism of stem cell based tissue engineering approach in spinal cord injury repair. Primary and secondary injury the damage the spinal cord tissue including neural cell death, nerve fiber breakage, hemorrhagic necrosis and edema and demyelination. With the persistence of inflammation, the glial scars and cavities form, as a barrier for neuroregeneration (A). Possible mechanism of stem cell based tissue engineering approach in spinal cord injury repair, such as the physical support from the biomaterials to fill in the cavities and to work as scaffold for donor and host to migrate and reside. Some biomaterials may contain anti glia scar elements that can promote nerve regeneration. The donor stem cells can differentiate into neurons or glia cells to replenish the lost cells. They can also rectify local hostile microenvironment through secretion of beneficial trophic factors and extracellular matrix (B).

compactness nature of spinal cord, it's better to select degradable biomaterials with an adjustable degeneration rate to make room for regenerating tissue

\section{(5) Surface property.}

The chemical or topological features of the biomaterials should be designed to facilitate cell adhesion and help to induce tissue regeneration. The biomaterials used for scaffold fabrication can be natural or synthetic polymers. Each of those has their own advantages and disadvantages [10]. In this review, we'll address the recent advancement using tissue engineering repair strategy for SCI treatment.

\section{Naturally Derived Biomaterials in Stem Cell Based Spinal Cord Engineering}

Natural polymers are easily obtained from natural sources and they have certain predictable physical, mechanical and biologic properties since they undergo highly controlled synthesis, resulting in regular structures. They are biodegradable and contain signals for cell adhesion; however, they are also hard to be sterilized, thereby often containing contaminating molecules. Another concern is the low reproducibility of the research results, since sometimes the exact compositions are unknown, and it is impossible to discuss how they interact with the stem cells and then impact on the outcomes [10,11]. The fast biodegradation rate of natural materials (i.e., collagen) and the low mechanical strength come as great disadvantages, which need to be addressed via cross-linking techniques in order to achieve the optimal results [12]. In order to reconstruct the functionalized tissue with good integration with the host, biocompatible materials are needed to fulfill the cysts and support the neural regeneration process.

\section{Fibrin}

Fibrin is a broadly used naturally derived polymer for spinal cord tissue engineering that has been shown to reduce glial scar formation at the host-material interface and could enhance tissue integration in rat model $[13,14]$. Highly purified embryonic stem cells (ES)-derived neural progenitor cells were embedded into 3D fibrin scaffolds then transplanted into sub-acute SCI resulted in high viability of donor cells and yield of differentiated neurons, oligodendrocytes and astrocytes. The differentiated oligodendrocytes participated in remyelination 
indicating the functional maturity of the donor cells. The loaded neurotrophine-3 (NT-3), platelet-derived growth factor (PDGF)AA did not influence the cell behavior much, meaning that the fibrin scaffolds provided a favorable environment for the cells [15]. A more significant morphological integration of donor cells and the host tissue was carried out by combining of human Neural Stem Cells (NSCs) and a group of trophic factors into fibrin matrices for implantation into rats with T3 complete spinal cord transection. The grafted NSCs derived neurons extended many axons into the host spinal cord for long distances to $\mathrm{L} 1$ and $\mathrm{C} 4$ segments, while host axons also penetrated grafts in the lesion sites. There was plenty synaptic structure forming as suggested by positive immunostaining of synaptic markers [16]. A following replication study confirmed that transplants of NSCs embedded in fibrin can fill lesion cavities with robustly extend axons. However, there was a discrepancy in continuous bridge of neural tissue between rostral and caudal segments [17].

\section{Collagen}

Collagen is a major protein that constructs ECM in most of mammal tissues which contains 29 different types and is mainly synthesized by fibroblasts [18]. Among all the subtypes, type I collagen is the most commonly adapted in tissue engineering. Gel formation can be controlled by temperature and $\mathrm{pH}$ and can be used in a large range of gel concentration. Some modified collagen can also be cross-linked by other methods to improve its stiffness [19]. Primary NSCs derived from Sprague-Dawley rats were seeded into double-layer unequalhole collagen membrane (made from porcine tendons), followed by transplanting into rat spinal cord hemisection models in the acute phase. Four weeks post-injury, neuronal tissue filled the space in the transplantation group, but there were only irregular connective tissue or cavities in the untreated controls. The treated rats were able to step on the ground with plantar, in contrast with much poor hind limb motor function in the controls [20]. In another study, neural tube-like structure differentiated from hESC lines were seeded into collagen I scaffolds, and then implanted into rats with the hemi-section injury at T10-T11 level. Five weeks post-implantation, the hindlimb motor and the sensory function of the experimental group was significantly improved [21].

\section{Gelatin}

Gelatin as a denatured product of collagen contains multiple cell adhesion molecules and had been certified to support many kinds of stem cell proliferation and differentiation [22,23], therefore has been used frequently in spinal cord regeneration. With the opinion that bone marrow derived Mesenchymal Stem Cells (MSCs) could benefit spinal cord regeneration because of their neuroprotection and postinjury microenvironment modulating abilities, neuronal induced MSCs were encapsulated into 3D gelatin sponge scaffolds and then implanted into rat models with fully transected injury at T10 segments. Eight weeks after transplantation, the MSC-derived neuron-like cells maintained their synapse-like morphology in vivo and further formed connections with host neurites; the hind limb function of the treated rats was significantly improved, and the cortical motor evoked potential (CMEP) was also significantly recovered [24]. In other similar studies, NSCs plus gelatin treated group showed highest expression of laminin (a pro-neurogenic molecule) and decreased chondroitin sulfate proteoglycans which inhibit the axonal growth and neuroplasticity. The stem cell treated spinal cords had smaller cavities and less scaring scale, and myelinated nerve fibers and blood vessels both newly formed in the lesion area $[25,26]$.

\section{Hyaluronic acid (or hyaluronan, HA)}

HA is a predominant component of intercellular matrix of stem cell niche which protects cells from oxidative DNA damage [27]. It interacts with cells mainly through CD44 and RHAMM receptors $[28,29]$, but cannot crosslink to form hydrogel per se. Therefore, HA has been always used as side chains chemically modified product to facilitate gel formation [30-32] or as mixture with matrix forming polymers [33]. Blended HA with Methyl Cellulose (MC) was used to make an injectable rapidly inverse-gelling polymer which could gel at physiological temperature, and the gel was further formulated with PDGF-A via streptavidin-biotin system to apply for SCI repair. Neural Stem/Progenitor Cells (NSPCs) combined with HAMC gels were implanted into SCI rats created by clip compression at T2 segment 9 days after modeling. Nine weeks post SCI data indicated that the lesion size of the NSPC/HAMC-rPDGF-A treated group was reduced 52\% when compared to the cell transplant control group; the number of spared host oligodendrocytes was about $25 \%$ higher in rostral side. Thereafter, the motor control function was also improved in the HAMC filled group [34]. Astrocyte has been identified to have both promotional and inhibitory effect on SCI repair [35]. It's reported that the astrocytesHA Tetrasaccharide $\left(\mathrm{HA}_{4}\right)$ combination finally improved the motor function [36] based on the facts that $\mathrm{HA}_{4}$ augmented the benifical effect of astrocytes through upregulating brain derived neurotrophic factor (BDNF) and vascular endothelial growth factor (VEGF) expression in astrocytes. This phenomenon might probably due to the degradation of HA scaffolds relieved astrocytes proliferation inhibition [37].

\section{Matrigel}

Matrigel matrix is a commercialized product derived from Engelbreth-Holm-Swarm (EHS) mouse sarcoma which contains multiple macromolecules such as laminin, collagen IV and entactin. It also contains a series of growth factors at different concentration, including EGF, bFGF, NGF, PDGF, IGF- 1 and TGF- $\beta$. These features suggest matrigel may be quite friendly for cell culture and tissue regeneration [38]. MSCs derived from fat tissue, bone marrow, Wharton's Jelly and umbilical cord blood (UCB) were delivered in Matrigel to compression injured spinal cord in order to evaluate the optimal seeded cell type for tissue repair. Matrigel-MSCs compound was injected around the lesion area and directly into the epicenter of the injured tissue. Their data demonstrated that the survived MSCs rarely transformed to neural cells but they migrated toward neural cells to modulate the neuroinflammation by reducing COX-1 and IL-6 and prevent astrocytosis. The authors concluded that there was no significant difference among all kinds of MSCs in the treatment of compression induced SCI, while UCB-MSCs significantly attenuated inflammation and favored spinal cord regeneration [39]. Another group induced human bone marrow stromal cells (hBMSC) into Schwann Cells (SC) in vitro, and then transplanted these pre-induced cells capsuled with matrigel into contusion injured rat spinal cord one week after injury. Five weeks after transplantation, although only a small percentage of cells survived, the cystic cavity turned significantly smaller than that the control group. Rats had escalated hindlimb motor function recovered. Although remyelination was observed in electron microscope images near the lesion site, the authors believed that those were the hBMSC-SC secreted neurotrophic factors, such as VEGF, TIMP-1 and -2 contributed to functional recovery, rather than the integration of transplanted cells into the host tissue [40].

There are also some well integrated and functionalized spinal cord regeneration achievements on agarose [41,42], alginate [43], chitosan [44] or self-assembling peptides [45]. 


\section{Synthetic Biomaterial in Stem Cell Based Spinal Cord Engineering}

Synthetic biomaterials embrace two advantages, i.e., easy to sterilize and easy to control and modify key parameters (e.g., porosity, architecture, stiffness, degradation rate) according to the needs. Synthetic biomaterials are capable to be manipulated in order to suit a specific tissue engineering application. For examples, their stiffness can be designed to regulate stem cell differentiation, degradation time can be adjusted to match the tissue formation rate and the gelation time of injectable polymers can be tailored to perfectly fulfill the lesion area at the desired time points. Although synthetic biomaterials lack of recognizable signals and are usually considered to have poor biocompatibility, it's feasible to overcome these hurdles through biofunctionalization processes [10,11]. Functionalized synthetic polymers could also be designed as drug/gene delivery vehicles while they are being used as scaffolds [46]. Here, we summarize some of the most commonly used biomaterials for their application in SCI repair studies.

\section{Poly-lactic acid (PLA)}

PLA has been used for a long time in clinic as absorbable suture material, and also serves as soft tissue augmentation [47]. PLA is polyester that hydrolyzes and releases lactide in vivo, which as a result will decrease local $\mathrm{pH}$ around the grafts [48]. Early study adapted a phase separation PLA preparation method which had great achievements in spinal cord regeneration [49]. PLA foam was fabricated with linear channels inside, and then implanted the form into both chronic and acute rat SCI model with hemisection lesion at T8 level for $2 \mathrm{~mm}$ in length. Two weeks post-implantation, numerous cells were observed in full length of the channels, among which were p75 positive SCs as well as GAP-43+ (an axonal growth factor) cells. Laminin, which stimulates neurite outgrowth, was stained intensely besides the SCs inside channels. An intersting phenomenon was that there was no astrocyte found in the channels, while they only accumulated around the lesion site but did not migrate in. Similarly, very few macrophages were stained inside the PLA filling, indicating the host had low inflammatory response to the material [50].

\section{Poly (lactic-co-glycolic acid) (PLGA)}

Poly (glycollic acid) (PGA) is a biodegradable, thermoplastic polymer with simple linear structure. Due to its high modulus, low solubility and brittle nature, there is no report about PGA application in spinal cord tissue engineering. However, when PLA and PGA are co-polymerized, the stiffness and degradation time of the product PLGA could be regulated by changing the ratio of the two components. PLGA is one of the most widely used synthetic materials in biomedical practices. Early study implanted human neural stem cells (clone HFB2050) seeded PLGA porous scaffolds into an adult rat hemi-section SCI model promoted long-term improvement in function (persistent for 1 year in some animals) relative to a lesion-control group. This study may suggest a new approach to SCI and, more broadly, may serve as a prototype for multidisciplinary strategies against complex neurological problems [51]. Later study engaged 2 African green monkeys experienced hemi-section at T9-T10 level in acute phase. The PLGA scaffolds with the lactide/glycolide ratio of 50:50 were fully degraded within the time frame of 41-81 days post implantation. The motor function scores in all subjects recovered better with time went on, and there was significant difference on the influenced left hind limb between PLGA plus hNSCs subjects (scored 15) and matrix only (one subject, scored 10) control. Interestingly, the matrix control also had better performance than non-treated control (one subject, scored 6), which indicated the physical support function of scaffold may help to reconstruct local disturbed circuits to regain function [52]. Animal studies with using PLGA and stem cells showed PLGA is an effective cell delivery scaffold with benign cytocompatibility and histocompatibility since it triggers mild immune/inflammation responses but facilitates seeded cells to integrate into host tissue after spinal cord injury $[53,54]$.

\section{Polyethylene glycol (PEG)}

PEG is a hydrophilic polymer well known well fusogen, and had multiple applications in spinal cord tissue engineering because it mediates membrane repair of primary spinal cord injury and reduces secondary spinal cord injury lead by oxidative stress [55]. A recent report used PEG scaffolds with seeded mouse bone marrow derived MSCs to treat transected SCI at T10 level on mouse model suggested with the combined treatment, less GFAP positive reactive astrocytes were observed throughout both grey and white matters meanwhile more MAP-2 positive neurons preserved in grey matter [56]. As PEG per se is not intrinsically degradable and lacks of cell adhesion capability, it has many limitations in tissue engineering applications. Oligo[(polyethylene glycol) fumarate] (OPF) is a novel PEG based oligomer hydrogel featuring degradable fumarate ester groups [57]. OPF can be cross-linked by UV light and more importantly, its molecular weight controls the mechanical properties and degradation speed of the hydrogel. These properties make it broadly used in bone [58], osteochondral [59], musculotendinous [60], cardiovascular [61] and neural tissue engineering [62,63]. OPF could serve as spinal cord regeneration matrix mainly due to its compressive and flexural modulus which is similar to that of rat spinal cord [64]. When OPF mixed with PLGA at (50:50) ratio, the scaffold was designed to deliver dibutyryl cyclic adenosine monophosphate (dbcAMP) in order to enhance the neurite outgrowth. Bone marrow derived MSCs were suspended in matrigel and seeded into scaffolds and transplanted into transected rat spinal cord injury model. The authors believed the sustained release of dbcAMP rescued axonal regeneration from MSCs induced inhibition and capillary formation, which in turn improved motor function [62].

\section{Poly- $\varepsilon$-caprolactone (PCL)}

PCL is one kind of biodegradable polyester and a semicrystalline polymer with regular structure resulting in high stiffness [65]. PCL was used as a bridging scaffold and a cell deliver vehicle as well in a rat hemi-section model. The cells involved were either human NSC line (F3) or NT3 gene engineered F3 NSCs (F3.NT3). Cell seeded PCL scaffolds were transplanted into the lesion sites immediately after injury, then chondroitinase $\mathrm{ABC}$ (C-ase) was pumping into the subarachnoid space steadily for 28 days. Rats in PCL plus F3.NT3 group had best locomotor recovery (on both BBB score and grid walk tests) and much improved motor evoked potentials 7 weeks post-SCI. Both F3 and F3.NT3 cells migrated into the host tissue, but only few of them (about 10\%) differentiated into MAP-2 positive neurons. F3.NT3 cells more frequently differentiated into oligodendrocytes than F3 cells. Meanwhile, the NSCs remained in PCL scaffolds did not terminate to neural cells. C-ase effectively abolished chondroitin sulfate proteoglycans around the injured tissue and enhanced NSC migration and axon regeneration [66]. The high stiffness and lengthy degradation time limited the application of PCL in neural tissue engineering. However, a simple way to solve this problem is physically blending two or more synthetic polymers together as a scaffold. For examples, in an aligned PCL/PLGA scaffold fabricated by electrospun technique, the weight ratio of PCL/PLGA was 4.5:5.5, with the ratio of lactide/ 
glycolide at 75:25 and average molecular weight of $105 \mathrm{kDa}$. In doing so, the advantages of PCL in contributing long term mechanical strength and PLGA in facilitating cell adhesion and proliferation were bound together. The authors also adapted dental follicle cells (DFC), which have multipotential differentiation abilities [67] in the study. DFCs adhered on the scaffolds tightly after overnight culture and deposited certain amount of ECM. This cell seeded scaffold at size $2 \mathrm{~mm} \times 10 \mathrm{~mm}$ was rolled and fit into the hemi-section lesion at T10-T11 level. Eight weeks post transplantation; the DFCs were detected to differentiate into oligodendrocyte precursors but not neurons or astrocytes. The authors considered the differentiated cells could replace the lost oligodendrocytes and remyelinate the survived fibers [68].

\section{Clinical Trials}

Compared to the in vitro assay and in vivo animal studies, clinical trials of spinal cord tissue engineering have rarely been performed. Although most of trials are at early stage, some of them hold high potentials for further development. Given the limitations of animal models and the differences between animal and human physiology, experience gained on animals interpreted judiciously before clinical translation.

Acid fibroblast growth factor (aFGF) and fibrin glue have been used in combination with total laminectomies and neurolysis in two trials which lasted 24 months [69,70]. The authors claimed that after the 2 years treatment, the American Spinal Injury Association (ASIA) motor scores, sensory scores, neurological levels and impairment scales were all significantly improved in both cervical and thoracolumbar groups. However, these were single-arm, nonrandomized trials with no control group. More cases should be included to compressively assess the real function of this treatment.

Abdel-Aziz and his colleagues applied peripheral nerve grafts plus chitosan-laminin scaffolds combines with the patients' autologous bone MSCs on 14 patients with chronic spinal cord injuries. The patients were with complete traumatic paraplegia leaded by complete cord disruption and defects. The MSCs were induced toward neural stem cell-like cells before mixing into the scaffolds. Patients' sural nerves from both sides were served as grafts. After surgery, both motor and sensory functions were improved on all patients. Compared to the reported surgery only cases [71], these 14 patients were better recovered on the point of muscular activities although they were still unable to stand erect and hold their knees extended while walking unaided. Seroma would be a complication related to chitosan disintegration [72].

\section{Summary}

There have been considerable advances in stem cell based tissue engineering for the treatment of SCI, some of which have entered clinical trials. Stem cells provide a cell source that may serve as substitutes to replace the lost cells, to rescue the impaired cells and maintain homeostasis of microenvironment through secretion of trophic factors and beneficial ECMs. Biomaterials are not only used as cell delivery vehicles but also as scaffolds to fill the cavity of lesioned spinal cord tissue in order to provide a physical microenvironment so that cells from surrounded normal tissue could migrate inside and execute their functions. More importantly, stem cells and biomaterials should be designed as functional entity, which interact with each other to facilitate neural tissue repair. Stem cells can be acquired from autologous sources, which may decrease the risk of immune response, especially with the development of induced pluripotent stem cells. Designing and synthesizing appropriate biomaterials should bring new insights into their cytocompatibility and their integration with host tissue. Benefits, drawbacks and translational potential of stem cell based tissue engineering for the treatment of SCI should be evaluated thoroughly and carefully. Nevertheless, with the rapid developments of stem cell and biomaterials technologies, the application of a combination of these two disciplines will provide promising therapeutic regimens to SCI repair.

\section{References}

1. (2014) Spinal cord injury facts and figures at a glance. J Spinal Cord Med 37 659-660.

2. Singh A, Tetreault L, Kalsi-Ryan S, Nouri A, Fehlings MG (2014) Global prevalence and incidence of traumatic spinal cord injury. Clin Epidemiol 6: 309331.

3. Jain NB, Ayers GD, Peterson EN, Harris MB, Morse L, et al. (2015) Traumatic spinal cord injury in the United States, 1993-2012. JAMA 313: 2236-2243.

4. Majdan M, Brazinova A, Mauritz W (2015) Epidemiology of traumatic spinal cord injuries in Austria 2002-2012. Eur Spine J .

5. Schwab ME (2002) Repairing the injured spinal cord. Science 295: 1029-1031

6. Thuret S, Moon LD, Gage FH (2006) Therapeutic interventions after spinal cord injury. Nat Rev Neurosci 7: 628-643.

7. Snyder EY, Teng YD (2012) Stem cells and spinal cord repair. N Engl J Med 366: 1940-1942.

8. Cregg JM, DePaul MA, Filous AR, Lang BT, Tran A, et al. (2014) Functional regeneration beyond the glial scar. Exp Neurol 253: 197-207.

9. Filli L1, Schwab ME (2012) The rocky road to translation in spinal cord repair Ann Neurol 72: 491-501.

10. Kubinová S, Syková E (2012) Biomaterials combined with cell therapy for treatment of spinal cord injury. Regen Med 7: 207-224.

11. Saracino GA, Cigognini D, Silva D, Caprini A, Gelain F (2013) Nanomaterials design and tests for neural tissue engineering. Chem Soc Rev 42: 225-262.

12. Ahn JI, Kuffova L, Merrett K, Mitra D, Forrester JV, et al. (2013) Crosslinked collagen hydrogels as corneal implants: effects of sterically bulky vs. non-bulky carbodiimides as crosslinkers. Acta Biomater 9: 7796-7805.

13. Taylor SJ, Rosenzweig ES, McDonald JW 3rd, Sakiyama-Elbert SE (2006) Delivery of neurotrophin-3 from fibrin enhances neuronal fiber sprouting after spinal cord injury. J Control Release 113: 226-235

14. Johnson PJ, Parker SR, Sakiyama-Elbert SE (2010) Fibrin-based tissue engineering scaffolds enhance neural fiber sprouting and delay the accumulation of reactive astrocytes at the lesion in a subacute model of spinal cord injury. J Biomed Mater Res A.92: 152-163.

15. McCreedy DA, Wilems TS, $\mathrm{Xu} \mathrm{H}$, et al. (2014) Survival, Differentiation, and Migration of High-Purity Mouse Embryonic Stem Cell-derived Progenitor Motor Neurons in Fibrin Scaffolds after Sub-Acute Spinal Cord Injury. Biomater Sci.2: 1672-1682.

16. Lu P, Wang Y, Graham L, McHale K, Gao M, et al. (2012) Long-distance growth and connectivity of neural stem cells after severe spinal cord injury. Cell 150 : 1264-1273.

17. Sharp KG, Yee KM, Steward O (2014) A re-assessment of long distance growth and connectivity of neural stem cells after severe spinal cord injury. Exp Neurol 257: $186-204$

18. Gorgieva S, Kokol V (2011) Collagen-vs. gelatine-based biomaterials and their biocompatibility: review and perspectives. INTECH Open Access Publisher.

19. Heo J, Koh RH, Shim W, Kim HD, Yim HG, et al. (2015) Riboflavin-induced photo-crosslinking of collagen hydrogel and its application in meniscus tissue engineering. Drug Deliv Transl Res .

20. Yuan N, Tian W, Sun L, Yuan R, Tao J, et al. (2014) Neural stem cell transplantation in a double-layer collagen membrane with unequal pore sizes for spinal cord injury repair. Neural Regen Res 9: 1014-1019.

21. Hatami M, Mehrjardi NZ, Kiani S, Hemmesi K, Azizi H, et al. (2009) Human embryonic stem cell-derived neural precursor transplants in collagen scaffolds promote recovery in injured rat spinal cord. Cytotherapy 11: 618-630. 
22. Faghihi $F$, Mirzaei $E, A i ~ J$, et al Differentiation potential of human chorionderived mesenchymal stem cells into motor neuron-like cells in two- and threedimensional culture systems. Mol neurobiol. DOI 10.1007/s12035-015-9129-y

23. Lim TC, Toh WS, Wang LS, Kurisawa M, Spector M (2012) The effect of injectable gelatin-hydroxyphenylpropionic acid hydrogel matrices on the proliferation, migration, differentiation and oxidative stress resistance of adult neural stem cells. Biomaterials. 33: 3446-3455.

24. Zeng X, Quu XC, Ma YH, Duan JJ2, Chen YF3, et al. (2015) Integration of donor mesenchymal stem cell-derived neuron-like cells into host neural network after rat spinal cord transection. Biomaterials 53: 184-201.

25. Wang JM, Zeng YS, Wu JL, Li Y, Teng YD (2011) Cograft of neural stem cells and schwann cells overexpressing TrkC and neurotrophin-3 respectively after rat spinal cord transection. Biomaterials $32 \cdot 7454-7468$.

26. Lai BQ, Wang JM, Duan JJ, Chen YF, Gu HY, et al. (2013) The integration of NSC-derived and host neural networks after rat spinal cord transection. Biomaterials 34: 2888-2901.

27. Darzynkiewicz Z, Balazs EA (2012) Genome integrity, stem cells and hyaluronan. Aging (Albany NY) 4: 78-88

28. Aruffo A, Stamenkovic I, Melnick M, Underhill CB, Seed B (1990) CD44 is the principal cell surface receptor for hyaluronate. Cell 61: 1303-1313.

29. Choudhary M, Zhang X, Stojkovic P, Hyslop L, Anyfantis G, et al. (2007) Putative role of hyaluronan and its related genes, HAS2 and RHAMM, in human early preimplantation embryogenesis and embryonic stem cell characterization. Stem Cells 25: 3045-3057.

30. Lee F, Chung JE, Kurisawa M (2009) An injectable hyaluronic acid-tyramine hydrogel system for protein delivery. J Control Release 134: 186-193.

31. Fenn SL, Oldinski RA,2 (2015) Visible light crosslinking of methacrylated hyaluronan hydrogels for injectable tissue repair. J Biomed Mater Res B Appl Biomater .

32. Ballios BG, Cooke MJ, Donaldson L, Coles BL4, Morshead CM5, et al. (2015) A Hyaluronan-Based Injectable Hydrogel Improves the Survival and Integration of Stem Cell Progeny following Transplantation. Stem Cell Reports 4: 10311045.

33. Fuhrmann T, Obermeyer J, Tator CH, Shoichet MS (2015) Click-crosslinked injectable hyaluronic acid hydrogel is safe and biocompatible in the intrathecal space for ultimate use in regenerative strategies of the injured spinal cord. Methods.84: 60-69.

34. Mothe AJ, Tam RY, Zahir T, Tator CH, Shoichet MS (2013) Repair of the injured spinal cord by transplantation of neural stem cells in a hyaluronan-based hydrogel. Biomaterials 34: 3775-3783.

35. Sabelström H, Stenudd M, Réu P, Dias DO, Elfineh M, et al. (2013) Residen neural stem cells restrict tissue damage and neuronal loss after spinal cord injury in mice. Science 342: 637-640.

36. Wang J, Wang X, Wei J, Wang M (2015) Hyaluronan tetrasaccharide exerts neuroprotective effect and promotes functional recovery after acute spinal cord injury in rats. Neurochem Res. 40: 98-108.

37. Struve J, Maher PC, Li YQ, Kinney S, Fehlings MG, et al. (2005) Disruption of the hyaluronan-based extracellular matrix in spinal cord promotes astrocyte proliferation. Glia 52: 16-24.

38. Hughes CS, Postovit LM, Lajoie GA (2010) Matrigel: a complex protein mixture required for optimal growth of cell culture. Proteomics 10: 1886-1890.

39. Ryu HH, Kang BJ, Park SS, Kim Y, Sung GJ, et al. (2012) Comparison of mesenchymal stem cells derived from fat, bone marrow, Wharton's jelly, and umbilical cord blood for treating spinal cord injuries in dogs. J Vet Med Sci 74 1617-1630.

40. Kamada T, Koda M, Dezawa M, et al. (2011) Transplantation of human bone marrow stromal cell-derived Schwann cells reduces cystic cavity and promotes functional recovery after contusion injury of adult rat spinal cord. Neuropathology.31: 48-58.

41. Stokols S, Tuszynski MH (2006) Freeze-dried agarose scaffolds with uniaxia channels stimulate and guide linear axonal growth following spinal cord injury. Biomaterials 27: 443-451.

42. Gros T, Sakamoto JS, Blesch A, Havton LA, Tuszynski MH (2010) Regeneration of long-tract axons through sites of spinal cord injury using templated agarose scaffolds. Biomaterials 31: 6719-6729.
43. Wu S, Suzuki Y, Kitada M, Kitaura M, Kataoka K, et al. (2001) Migration, integration, and differentiation of hippocampus-derived neurosphere cells after transplantation into injured rat spinal cord. Neurosci Lett 312: 173-176.

44. Bozkurt G, Mothe AJ, Zahir T, Kim H, Shoichet MS, et al. (2010) Chitosan channels containing spinal cord-derived stem/progenitor cells for repair of subacute spinal cord injury in the rat. Neurosurgery 67: 1733-1744.

45. Iwasaki M, Wilcox JT, Nishimura Y, et al. (2014) Synergistic effects of selfassembling peptide and neural stem/progenitor cells to promote tissue repai and forelimb functional recovery in cervical spinal cord injury. Biomaterials. 35 2617-2629.

46. Kim M, Park SR, Choi BH (2014) Biomaterial scaffolds used for the regeneration of spinal cord injury (SCl). Histol Histopathol 29: 1395-1408.

47. Woerle B, Hanke CW, Sattler G (2004) Poly-L-lactic acid: a temporary filler for soft tissue augmentation. J Drugs Dermatol 3: 385-389.

48. Madigan NN, McMahon S, O'Brien T, Yaszemski MJ, Windebank AJ (2009) Current tissue engineering and novel therapeutic approaches to axonal regeneration following spinal cord injury using polymer scaffolds. Respir Physiol Neurobiol.169: 183-199.

49. Maquet V, Martin D, Scholtes F, Franzen R, Schoenen J, et al. (2001) Poly(D,L-lactide) foams modified by poly(ethylene oxide)-block-poly(D,Llactide) copolymers and a-FGF: in vitro and in vivo evaluation for spinal cord regeneration. Biomaterials 22: 1137-1146.

50. Cai J, Ziemba KS, Smith GM, Jin Y (2007) Evaluation of cellular organization and axonal regeneration through linear PLA foam implants in acute and chronic spinal cord injury. J Biomed Mater Res A 83: 512-520.

51. Teng YD, Lavik EB, Qu X, Park KI, Ourednik J, et al. (2002) Functional recovery following traumatic spinal cord injury mediated by a unique polymer scaffold seeded with neural stem cells. Proc Natl Acad Sci U S A 99: 3024-3029.

52. Pritchard CD, Slotkin JR, Yu D, et al. (2010) Establishing a model spinal cord injury in the African green monkey for the preclinical evaluation of biodegradable polymer scaffolds seeded with human neural stem cells. J neurosci methods.188: 258-269.

53. He L, Zhang Y, Zeng C, Ngiam M, Liao S, et al. (2009) Manufacture of PLGA multiple-channel conduits with precise hierarchical pore architectures and in vitro/vivo evaluation for spinal cord injury. Tissue Eng Part C Methods 15: 243 255 .

54. Zhang YQ, He LM, Xing B (2012) Neurotrophin-3 gene-modified Schwann cells promote TrkC gene-modified mesenchymal stem cells to differentiate into neuron-like cells in poly(lactic-acid-co-glycolic acid) multiple-channel conduit. Cells, tissues, organs 195: 313-322.

55. Shi $R(2013)$ Polyethylene glycol repairs membrane damage and enhances functional recovery: a tissue engineering approach to spinal cord injury Neurosci Bull 29: 460-466.

56. Oda Y, Tani K, Isozaki A, Haraguchi T, Itamoto K, et al. (2014) Effects of polyethylene glycol administration and bone marrow stromal cell transplantation therapy in spinal cord injury mice. J Vet Med Sci 76: 415-421.

57. Kinard LA, Kasper FK, Mikos AG (2012) Synthesis of oligo(poly(ethylene glycol) fumarate). Nat Protoc 7: 1219-1227.

58. de Girolamo L, Niada S, Arrigoni E, Di Giancamillo A, Domeneghini C, et al (2015) Repair of osteochondral defects in the minipig model by OPF hydrogel loaded with adipose-derived mesenchymal stem cells. Regen Med 10: 135151.

59. Lim CT, Ren X, Afizah MH, et al. (2013) Repair of osteochondral defects with rehydrated freeze-dried oligo[poly(ethylene glycol) fumarate] hydrogels seeded with bone marrow mesenchymal stem cells in a porcine model. Tissue engineering. Part A. 19: 1852-1861.

60. Qiu Y, Lim JJ, Scott L Jr., Adams RC, Bui HT, Temenoff JS (2011) PEG-based hydrogels with tunable degradation characteristics to control delivery of marrow stromal cells for tendon overuse injuries. Acta Biomater.7: 959-966.

61. Wang H, Liu Z, Li D, Guo X, Kasper FK, et al. (2012) Injectable biodegradable hydrogels for embryonic stem cell transplantation: improved cardiac remodelling and function of myocardial infarction. J Cell Mol Med 16: 1310-1320.

62. Rooney GE, Knight AM, Madigan NN ( 2011) Sustained delivery of dibutyry cyclic adenosine monophosphate to the transected spinal cord via oligo [(polyethylene glycol) fumarate] hydrogels. Tissue engineering. Part A $17: 1287-1302$ 
Citation: Niu W, Zeng X (2015) The Application of Stem Cell Based Tissue Engineering in Spinal Cord Injury Repair. J Tissue Sci Eng 6: 158. doi:10.4172/2157-7552.1000158

63. Hakim JS, Esmaeili Rad M, Grahn PJ, et al. (2015) Positively charged oligo[poly(ethylene glycol) fumarate] scaffold implantation results in a permissive lesion environment after spinal cord injury in rat. Tissue engineering. Part A.21: 2099-2114.

64. Chen BK, Knight AM, Madigan NN, Gross L, Dadsetan M, et al. (2011) Comparison of polymer scaffolds in rat spinal cord: a step toward quantitative assessment of combinatorial approaches to spinal cord repair. Biomaterials 32 : 8077-8086.

65. Abedalwafa M, Wang F, Wang L, Li C (2013) BIODEGRADABLE POLYEPSILON-CAPROLACTONE (PCL) FOR TISSUE ENGINEERING APPLICATIONS: A REVIEW. Rev. Adv. Mater. Sci.34: 123-140.

66. Hwang DH, Kim HM, Kang YM, Joo IS, Cho CS, et al. (2011) Combination of multifaceted strategies to maximize the therapeutic benefits of neural stem cell transplantation for spinal cord repair. Cell Transplant 20: 1361-1379.

67. Chen G, Sun Q, Xie L, Jiang Z, Feng L, et al. (2015) Comparison of the Odontogenic Differentiation Potential of Dental Follicle, Dental Papilla, and Cranial Neural Crest Cells. J Endod 41: 1091-1099.
68. Li X, Yang C, Li L, Xiong J, Xie L, et al. (2015) A therapeutic strategy for spinal cord defect: human dental follicle cells combined with aligned PCL/PLGA electrospun material. Biomed Res Int 2015: 197183.

69. Wu JC, Huang WC, Tsai YA, Chen YC, Cheng H (2008) Nerve repair using acidic fibroblast growth factor in human cervical spinal cord injury: a preliminary Phase I clinical study. J Neurosurg Spine. 8: 208-214.

70. Wu JC, Huang WC, Chen YC, Tu TH, Tsai YA, et al. (2011) Acidic fibroblast growth factor for repair of human spinal cord injury: a clinical trial. J Neurosurg Spine 15: 216-227.

71. Tadie M, Liu S, Robert R, Guiheneuc P, Pereon Y, et al. (2002) Partial return of motor function in paralyzed legs after surgical bypass of the lesion site by nerve autografts three years after spinal cord injury. J Neurotrauma 19: 909-916.

72. Amr SM, Gouda A, Koptan WT (2014) Bridging defects in chronic spinal cord injury using peripheral nerve grafts combined with a chitosan-laminin scaffold and enhancing regeneration through them by co-transplantation with bonemarrow-derived mesenchymal stem cells: case series of 14 patients. J Spinal Cord Med.37: 54-71. 